\title{
Development of psychophysiological motoric reactivity is influenced by peripubertal pharmacological inhibition of gonadotropin releasing hormone action - Results of an ovine model ${ }^{\text {is }}$
}

\author{
Neil P. Evans ${ }^{a, *}$, Jane E. Robinson ${ }^{\text {a }}$, Hans W. Erhard ${ }^{\text {b }}$, Erik Ropstad ${ }^{c}$, \\ Lynne M. Fleming ${ }^{a}$, Ira Ronit Hebold Haraldsen ${ }^{\text {d }}$
}

\footnotetext{
${ }^{a}$ Institute of Biodiversity, Animal Health and Comparative Medicine, College of Medical, Veterinary and Life Sciences, University of Glasgow, G61 $1 \mathrm{QH}$, Scotland, UK

${ }^{\mathrm{b}}$ AgroParisTech /INRA, UMR 791 Modélisation Systémique Appliquée aux Ruminants, 16 rue Claude Bernard, F-75231 Paris, France

${ }^{\mathrm{c}}$ Faculty of Health Sciences, Oslo University College, Pb 4 St. Olavs plass, 0130 Oslo, Norway

${ }^{\mathrm{d}}$ Department of Neuropsychiatry and Psychosomatic Medicine, Oslo University Hospital-Rikshospitalet, Sognsvannsveien 20, 0027 Oslo, Norway
}

Received 27 October 2011; received in revised form 21 March 2012; accepted 26 March 2012

\author{
KEYWORDS \\ GnRH; \\ Psychophysiological \\ motoric reactivity; \\ Emotional reactivity; \\ Sheep; \\ Puberty; \\ Stress; \\ Cortisol; \\ GnRH agonist
}

\begin{abstract}
Summary This study reports the effects of peripubertal GnRH receptor inactivation on development of psychophysiological motoric reactivity (PMR; sometimes also called emotional reactivity), plasma cortisol concentrations and the relationship between plasma cortisol and PMR in male and female sheep.

The study formed part of a larger trial and utilised 46 same sex twins. One twin remained untreated (control) while the other received a subcutaneous GnRH agonist (GnRHa GoserelinAcetate) implant every 4th week, beginning at 8 and 28 weeks of age, in males and females, respectively (different, due to sex specific age of puberty). PMR, a measure of an animals' response to social isolation, was measured over a two minute period at 8,28 and 48 weeks of age, using a three axis accelerometer. During the test period vocalisation rate was recorded. Cortisol was assayed in blood samples collected on a single day when animals were 40 weeks of age.

PMR and vocalisation rate were significantly higher in females than males at all ages tested. At 28 weeks of age ( 20 weeks treatment) PMR was increased in treated males to the level seen in control females, by 48 weeks of age treated males' PMR was significantly less than controls. In females, 20 weeks of GnRHa treatment (28-48 weeks of age) was not associated with differences in PMR. Cortisol concentrations were significantly higher in females than males but were not
\end{abstract}

\footnotetext{
The Sex On Brain European Research Group - SOBER.

* Corresponding author. Tel.: +44 141330 5795; fax: +44 1413305797.

E-mail address: neil.evans@glasgow.ac.uk (N.P. Evans).
} 
affected by treatment. Plasma cortisol concentrations were positively correlated with PMR; this relationship being driven by the treated animals in both sexes.

The results demonstrate that PMR is sexually dimorphic and cortisol dependent in sheep from at least 8 weeks of age. Importantly, they also demonstrate that long-term treatment of males with a GnRH agonist results in changes in age-dependent development of PMR.

(C) 2012 Elsevier Ltd. All rights reserved.

\section{Introduction}

Gonadotropin releasing hormone (GnRH), as suggested by its name, has been considered predominantly a reproductive hormone it's major function being the central control of reproductive physiology and behaviour. Recent evidence, however, supports a much wider physiological remit, with roles in cardiovascular (Skinner et al., 2009; Wojniusz et al., 2011) and smooth muscle function (Reichler et al., 2006; Arnold et al., 2009; Coit et al., 2009) and a significant role in cognitive function (Grigorova et al., 2006; Bryan et al., 2009; Wojniusz et al., 2011). With regard to the latter, GnRH receptor (GnRHR) expression has been demonstrated throughout the mammalian brain including regions related to learning and cognition such as the hippocampus (Albertson et al., 2008; Skinner et al., 2009; Chu et al., 2010; Rosati et al., 2011; Schang et al., 2011). Empirical support for a role in cognition is also available; as cognitive side effects have been described following $\mathrm{GnRH}$ analogue (GnRHa) administration in a number of studies in adult humans (Meethal et al., 2005; Grigorova et al., 2006; Nelson et al., 2008; Palomba et al., 2008; Bryan et al., 2009).

A recent review of $\mathrm{GnRHa}$ therapy has reported significant impairment of cognitive function, especially in domains of visuo-spatial and higher-order executive control functions in men following GnRHa treatment for prostate cancer (Nelson et al. , 2008). Similarly, in pre-menopausal women treated with GnRHa a decline in cognitive function has been reported (Sherwin and Tulandi, 1996; Palomba et al., 2004, 2008; Andreano et al., 2011). While it could be argued that some of these clinical results are secondary to the reduction in gonadal steroids following GnRHa treatment, results from experimental studies in animals have indicated that $\mathrm{GnRH}$ may have beneficial effects with regard to cognitive function in models of Alzheimer's disease (Casadesus et al., 2006; Bryan et al. , 2009) and a GnRH-1 receptor agonist has recently entered phase III clinical trials in the US for treatment of Alzheimer's disease (ALADDIN Study - Phase III: Antigonadotropin-Leuprolide in Alzheimer's Disease Drug Investigation (VP-AD-301)). Mechanistically, the effects of GnRH on brain function have been proposed to be due to gonadotropins' ability to trigger mitotic division in quiescent (G0 phase) neurons (Bowen et al., 2002; Harris et al., 2002; Mattson et al., 2004). While such effects of $\mathrm{GnRH}$ on cognition have been reported in adults, there is an almost complete lack of trials exploring possible effects of chronic GnRHa treatment on cognitive brain development and behaviour in children and adolescents, despite their widespread use for treatment purposes (where the aim is normally either to prevent or delay the sexual maturation and its secondary implications); i.e. central precocious puberty (CPP), gonadal protection for children undergoing chemotherapy, idiopathic short stature, severe hypothyroidism, growth hormone deficiency, congenital adrenal hyperplasia, and even autism (Carel et al., 2009). Despite the lack of specific evidence in children about possible extragonadal effects of $\mathrm{GnRH}$ analogues their safety has been supported by the recently published Consensus Statement on the Use of Gonadotropin-Releasing Hormone Analogues in Children (Carel et al., 2009).

As part of major study, in which we have characterised the effects of peripubertal GnRHa treatment, using a novel ovine animal model, we recently demonstrated that longterm, peripubertal GnRHa treatment had a significant impact on sex-specific brain development, which affected the regulation of behaviour and cardiac function in young animals (Wojniusz et al., 2011). Females in which the pubertal transition was blocked by GnRHa treatment displayed increased non-verbal cognitive function like anxiety and greatly pronounced avoidance behaviour, whereas males, in which puberty was similarly blocked, exhibited risk taking and exaggerated approach oriented behaviours, when the animals (both males and females) were tested at approximately 48 weeks of age, i.e. after the expected time of the pubertal transition (Wojniusz et al., 2011).

The possibility that blockade of $\mathrm{GnRH}$ actions during peripubertal development can lead to cognitive differences is of significant medical interest. This time period is characterised by dramatic changes in the patterns of endogenous GnRH secretion associated with final development and activation of the reproductive system but also coincides with the onset of numerous mental disorders which typically continue throughout adulthood (Neufang et al., 2009). According to the WHO, anxiety disorders have one of the youngest ages of onset (median, 15 years of age), followed by substance-use and mood disorders and, thus, onset typically falls within the timeframe during which large changes in $\mathrm{GnRH}$ secretion occur. Interestingly, as with the timing of puberty, the nature and time of onset of many human mental disorders is also sexual dimorphic. For example, between 6 and 12 years of age, two thirds of diagnosed mental problems occur in boys, the most common forms being hyperactivity, concentration/behavioural problems, anhedonia, and ADHD. After puberty, however, this balance shifts, such that two thirds of mental problems are seen in young women but they reported more anxiety and depressive symptoms (Nasjonalt folkehelseinstitutt, 2009; Naninck et al., 2011). Similarly, while the incidence of depressive illness is equal in prepubescent boys and girls, the chances of suffering from such a condition in later life is $50 \%$ greater in women than men (Pitychoutis et al., 2010; Naninck et al., 2011).

The peripubertal maturing brain is characterised by the development of sex-specific and non-sex-specific functional circuits, which develop according to distinct spatial-temporal patterns in each sex. Subcortical regions (e.g. striatum) mature functionally much faster than prefrontal top-down control regions, and disturbances in this maturation have been suggested as an explanation for observed insufficient behavioural changes during puberty and adolescence. In 
addition, these circuits develop differently in boys and girls (Sisk and Foster, 2004; Casey and Jones, 2010). GnRHR has been reported to be present in the affected brain regions, e.g. the hippocampus (CA1 to CA3) and amygdala, frontal cortex within the forebrain, such as Brodmann's area and the dentate gyrus (Skinner et al., 2009; Stewart et al., 2009). How GnRHa treatment may interfere with this maturation of the fronto-temporal-limbic circuit has not currently been determined.

While we recognise that is not possible to assess classically defined human emotions in animals, there is a body of literature supporting the use of behavioural and physiological measures as proxies for emotional reactions (reviewed Desire et al., 2002; Boissy et al., 2007). Psychophysiological motoric reactivity (PMR) is a form of emotional reactivity that has previously been shown to incorporate emotional elements of behaviour as well as the appearance of a motor reaction and provides a combined measure of fearfulness (Savage and Eysenck, 1964; Archer, 1973; Suarez and Gallup, 1983; Boissy, 1998). Interestingly, PMR is sexually dimorphic, with males being less reactive compared to females (Fordyce et al., 1988; Vandenheede and Bouissou, 1993), therefore, the potential exists that PMR could be controlled or altered by changes in reproductive hormone secretion during the pubertal transition. Physiologically, plasma cortisol is one of the key physiological regulators of the mammalian response to, or ability to cope with, stressful or fearful situations. Cortisol secretion is regulated via the hypothalamo-pituitary adrenal (HPA) axis, the activity of which, in the adult, is known to be influenced by events that occur during psychophysiological development (Meerlo et al., 1999; Meaney, 2001; Neal et al., 2004; Lippmann et al., 2007; Parfitt et al., 2007).

In the present project we thus wished to investigate the effects of peripubertal GnRHa treatment on aspects of PMR, i.e. the ability of an individual to control negative fearful emotions and behaviours, using our novel ovine animal model. An ovine model was chosen because of its relatively long period of brain maturation compared to other model species, e.g. rodents, and the previous use of sheep to investigate development of PMR (Erhard et al., 2004; Erhard and Rhind, 2004). Data obtained from this model will be compared to data obtained from our ongoing human studies.

\section{Methods}

\subsection{Animals}

This study was conducted using 46 sets of same sex twins (male 24, female 22) born at the University of Glasgow Cochno Research Centre $\left(55^{\circ} 55^{\prime} \mathrm{N}\right)$ between the 17 th March and $1 \mathrm{st}$ April 2008. Same sex twin were utilised to ensure that there were no effects on sexually differentiated traits, of steroid transfer between siblings during in utero development and higher genetic comparability. All animals were Scottish MuleTexel crosses. All animal procedures were carried out following approval of the University of Glasgow's Welfare and Ethics Committee and in accordance with Home Office regulations (PPL 60/3826). Male and female lambs were maintained separately throughout the study and lambs remained with their dams until weaned at about 12 weeks of age. At birth, within each set of twins, one lamb was randomly assigned to the treatment and the other the control group, thus minimising potential parental effects.

\subsection{GnRH agonist treatment}

Animals in the treatment groups received a subcutaneous implant of Goserelin-Acetate (Zoladex, kindly donated by Astra Zeneca, Macclesfield, UK, $3.6 \mathrm{mg}$ ) every 4th week beginning at 8 weeks of age in males and 28 weeks of age in females until the end of the study in March 2009. The start of treatment was approximately 2 weeks before the predicted time of puberty in each sex, the timing of puberty being sexually differentiated in this species (Wood and Foster, 1998), as in humans. This treatment resulted in suppression of development of the hypothalamo-pituitary-gonadal axis. PMR was assessed at 8,28 , and 48 weeks of age.

\subsection{PMR during confinement in a weigh crate}

At 8 weeks of age PMR was tested in a sub-sample of male $(n=24)$ and female $(n=21)$ animals but all animals at 28 and 48 weeks of age, using an established method which has been previously published (Erhard et al., 2004; Erhard and Rhind, 2004). Briefly, to facilitate ease of handling males and females were split into sub-groups (12-16 animals per subgroup) during the test periods. Animals were tested in a random order and handling before the test was kept to a minimum. Prior to being placed in the weigh crate, a subgroup of sheep was moved into a holding pen. Then one animal was moved into an area adjacent to the weigh crate, the gate to the crate was opened and the sheep allowed to enter the crate voluntarily. The sides of the crate were solid but the front and back gates were barred so sheep were visually isolated from their peers during the test and thus expected to experience activation of their sympathetic nervous systems. The movement of the crate was measured over a period of $120 \mathrm{~s}$ using a three-axes accelerometer as described previously (Erhard et al., 2004; Erhard and Rhind, 2004). The accelerometer collects movement data 100 times per second. These data were averaged into $15 \mathrm{~s}$ bins for analysis and both the maximum activity value per test (largest single movement/deflection of the animal in the crate) and the average activity value per bin were used for analysis. During the period of confinement in the crate the number of vocalisations was recorded.

\subsection{Blood sampling and measurement of circulating cortisol concentrations}

Plasma cortisol concentrations were measured in blood samples that had been collected, by jugular venipuncture, to assess pubertal development when animals were approximately 40 weeks of age. This specific sample was chosen for cortisol analysis as all animals were sampled on one day, over a short period of time, in the absence of behavioural tests and before GnRHa administration (to treated animals), thus animals had not been handled and seemed relatively unstressed. Plasma cortisol concentrations were measured in a single assay, using a commercial kit (Coat-a-Count, Siemens) from which the assay standards were diluted relative to the manufacturer's instructions such that the standard curve 
spanned $1.25-200 \mathrm{ng} / \mathrm{ml}$. Assay sensitivity was $1.05 \mathrm{ng} / \mathrm{ml}$ and the intra-assay coefficient of variation averaged $5 \%$.

\subsection{Statistical analyses}

All data are reported as means \pm SEM. Maximum activity (deflection) data was analysed for effects of sex (control animals at weeks 8, 28 and 48) or treatment (males, weeks 28 and 48; females, week 48) using Student's $t$-test. Average activity observed within the $120 \mathrm{~s}$ test period was split into eight 15 s intervals, log transformed to equalise variance and analysed for effects of time and either sex (control animals at weeks $8,28,48$ ) or treatment (males, weeks 28 and 48; females, week 48) and interactions between variables using 2 -way ANOVA. Number of vocalisations/15 s was also calculated and analysed as described for mean activity. Cortisol concentrations measured at $\sim 40$ weeks of age were analysed for effects of sex and treatment using 2-way ANOVA. The cortisol data ( $\sim 40$ weeks of age) and the mean activity and vocalisation data (48 weeks of age) were analysed for significant statistical bivariate correlations using Pearson's $(r)$ (activity data) and Spearman's (vocalisations) correlation $\left(r_{\mathrm{s}}\right)$ coefficients with a significance threshold for $P$ (two tailed) $<0.05$. All statistical analysis was done using commercial software (Graphpad Prism).

\section{Results}

\subsection{Average activity at 8 weeks of age}

Two-way ANOVA indicated significant effects of sex $(P<0.001)$ and time $(P<0.0005)$ on mean activity levels, Fig. 1. Activity levels started high in both sexes, but stabilised within $30-45 \mathrm{~s}$. Average activity levels were higher in females during six of the eight $15 \mathrm{~s}$ bins and post hoc tests indicated a significant $(P<0.05)$ sex-difference in activity levels in the $60-75 \mathrm{~s}$ time period.

\subsection{Average activity at 28 weeks of age}

Comparisons between control males and the females (all untreated at this point) indicated that activity levels were

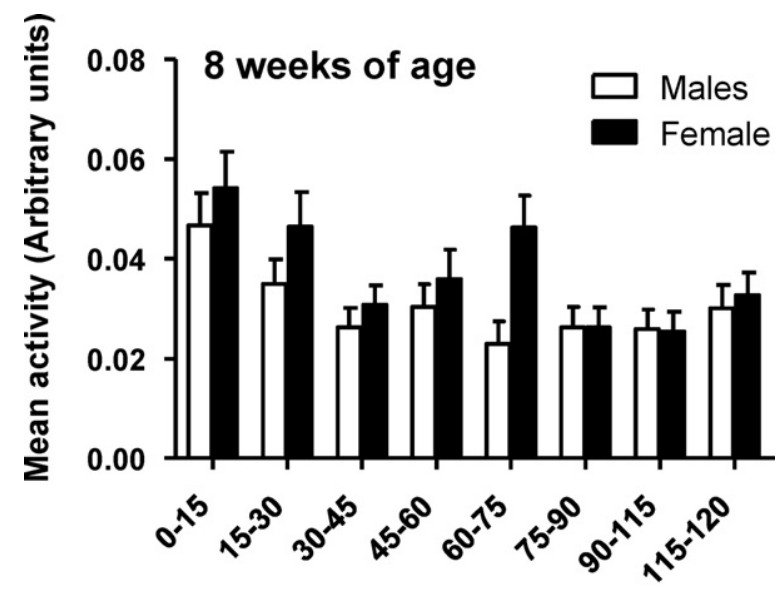

Time in weight crate (sec)

Figure 1 PMR (mean \pm S.E.M.), in lambs at 8 weeks of age, assessed as mean activity measured over eight $15 \mathrm{~s}$ time period using a three axes accelerometer. Data from male and female animals are depicted by the open and solid bars, respectively. At this time no animals had been treated with the GnRH agonist.

not significantly affected by time (data not shown) but remained significantly $(P<0.0005)$ higher in females than males (mean data presented in Fig. 2). At 28 weeks of age, half of the males had received GnRHa for 20 weeks but all females remained untreated. While there was no significant effect of time on mean activity levels in the males (data not shown), GnRHa treatment was associated with significantly $(P<0.005)$ increased mean activity levels. Interestingly, activity levels in the treated males were not different from those in untreated females $(P=0.27)$.

Analysis indicated no effect of time but a significant $(P<0.0001)$ effect of sex, on vocalisations (vocalisation/ $15 \mathrm{~s}$ bin); with mean vocalisation rate being higher in females compared to males. Vocalisation rate in males was not affected by treatment.

\subsection{Average activity at 48 weeks of age}

Comparison of mean activity levels between control males and control females did not reveal effects of time $(P=0.97)$

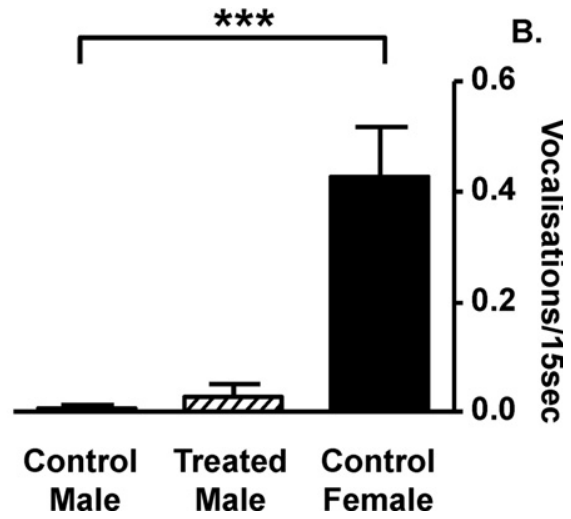

Figure 2 Mean \pm S.E.M. PMR/15 second bin (A) and mean \pm S.E.M. vocalisation rate/15 s bin (B) in lambs at 28 weeks of age. Data from control male and female animals are depicted by the open and solid bars, respectively. Hatched bars indicate males that had received GnRHa treatment from 8 weeks of age. ${ }^{*} P<0.005,{ }^{* *} P<0.0005,{ }^{* * *} P<0.0001$. 

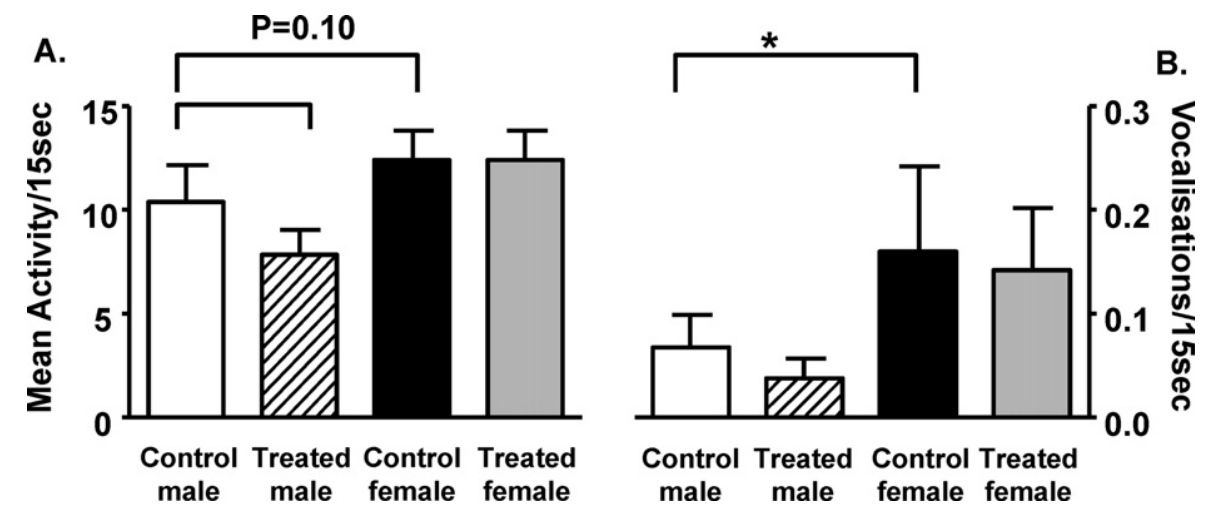

Figure 3 Mean \pm S.E.M. PMR/15 second bin (A) and mean \pm S.E.M. vocalisation rate/15 s bin (B) in lambs at 48 weeks of age. Data from control male and female animals are depicted by the open and solid bars, respectively. Hatched bars indicate males and grey bars females that had received GnRHa treatment from 8 and 28 weeks of age, respectively. ${ }^{*} P<0.05$.

but a significant effect of sex $(P<0.05)$, activity being higher in females than males. Similar to the results at 28 weeks of age, vocalisation rate was not affected by time but was significantly $(P<0.05)$ higher in control females than control males $(0.16 \pm 0.03$ vs $0.07 \pm 0.03$ vocalisations per $15 \mathrm{~s}$, respectively).

At this test point, approximately half of both males and females had received GnRHa treatment, although the duration of treatment differed in the two sexes. In the males, there was again no significant effect of time but a significant $(P<0.05)$ effect of treatment on mean activity levels, PMR being reduced in animals that had received the $\mathrm{GnRHa}$ treatment. As with the data collected at 28 weeks of age, there were no significant effects of time or treatment on vocalisations/15 s. In the females there were no significant effects of either time or treatment (Fig. 3) on mean activity levels or the number of vocalisations/15 s period.

\subsection{Maximum activity within the weight crate}

Maximum activity (maximum deflection/largest movement) was not affected by sex or treatment at any of the ages tested

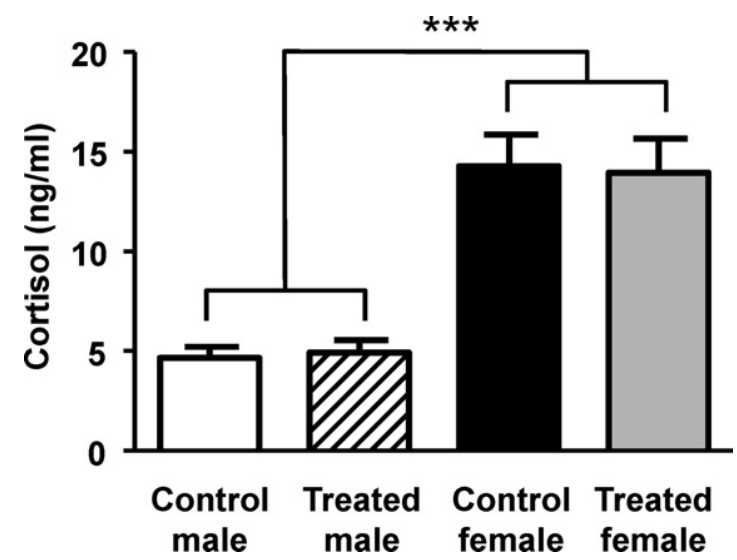

Figure 4 Mean plasma cortisol concentrations at 40 weeks of age. Data from control male and female animals are depicted by the open and solid bars, respectively. Hatched bars indicate males and grey bars females that had received GnRHa treatment from 8 and 28 weeks of age, respectively. ${ }^{* * *} P<0.001$.
(8 weeks, males $n=24,0.23 \pm 0.02$, females $n=21$, $0.25 \pm 0.03 ; 28$ weeks, control males $n=23,0.06 \pm 0.01$, treated males $n=24,0.17 \pm 0.04$, control females $n=43$, $0.09 \pm 0.01 ; 48$ weeks control males $n=22,7.12 \pm 1.22$, treated males $n=22,7.03 \pm 1.36$, control females $n=21$, $13.00 \pm 3.30$, treated females $n=21,8.42 \pm 1.7$ ).

\subsection{Plasma cortisol}

Mean cortisol concentrations are shown in Fig. 4. Mean plasma cortisol concentrations were significantly $(P<0.0001)$ higher in females compared to males, but were unaffected by $\mathrm{GnRHa}$ treatment. Statistical analysis indicated a significant $(P<0.05)$ positive relationship $(R=0.234)$ between cortisol and PMR across the entire data set $(n=84)$. Further analysis indicated that, when split by sex, there was no relationship between cortisol and mean activity levels in either males or females. When split by treatment, a significant positive correlation existed between plasma cortisol concentrations and PMR over the whole test period in treated (Pearson $R=0.37$, $P<0.05)$ but not control animals.

Analysis of the vocalisation data did not show an overall correlation $\left(r_{\mathrm{s}}=0.18, P=0.10\right)$ or a correlation when the data were split by sex (males $r_{\mathrm{s}} 0.15, P=0.33$; females $r_{\mathrm{s}}$ $0.10, P=0.54$ ) but as with the PMR data, showed a significant $(P<0.05)$ correlation with cortisol in treated $\left(r_{\mathrm{s}}=0.381\right)$ but not control animals.

\section{Discussion}

This study reports the effects on PMR, of pharmacological inhibition of $\mathrm{GnRH}$ action during the peripubertal period. Initial published work from this project has shown that peripubertal GnRHa treatment significantly affects sex-specific brain development, evidenced by its impact on behavioural and central cardiac regulation (Wojniusz et al., 2011). The results of the current study indicate that PMR is sexually differentiated from an early age, i.e. prior to puberty, being significantly higher in females than males. This extends previous data and suggests that the sexually differentiated nature of PMR in sheep may be prenatally programmed. Importantly, the results demonstrate, for the first time, that PMR changes over the peripubertal period in male sheep as in 
humans (Spear, 2009) and that these changes are influenced by the hormonal changes that occur during the peripubertal period. Specifically, blockade of GnRH action for 20 weeks that encompasses the peripubertal period in male sheep was associated with higher levels of PMR and the consequent loss of a sex difference in this characteristic ( 28 weeks of age). 40 weeks of GnRHa treatment, however, was associated with significantly reduced PMR compared to animals that had been allowed to progress through puberty normally (48 weeks of age). Unlike in males, 20 weeks of GnRHa treatment was not associated with any effects on PMR (at 48 weeks of age). The experimental design however, does not allow us to exclude an effect on PMR of more prolonged GnRHa exposure in female animals.

Across the whole data set, PMR at 48 weeks of age was positively correlated with plasma cortisol concentrations, mainly due to a relationship between these characteristics in the GnRHa treated animals.

The measure of PMR used in this study (Erhard et al., 2004; Erhard and Rhind, 2004), combines the likelihood of an animal responding to, and the reaction that an animal has to, a situation that induces fear, in this case social isolation. PMR in this paradigm can be assessed in multiple ways including maximum or average activity. Previous ovine studies (Erhard et al., 2004; Erhard and Rhind, 2004) have indicated sex differences in PMR when assessed as maximum activity. In the current study both maximum and average activity were analysed. While maximum activity was not found to differ, it exhibited the same patterns as average activity levels which differed significantly between groups at each tested age. It is likely that average activity provides a more robust measure of PMR as it reflects overall locomotor activity and is less likely to be influenced by any one specific movement.

The physiological response to isolation stress in sheep, has previously been reported to be stronger in females than males (Turner et al., 2002; Hernandez et al., 2009a,b) as has the behavioural stress response which is present from birth (Hernandez et al., 2009a,b). The results of this study confirm that both the physical manifestation of the animals psychological response to stress, i.e. its PMR (at 8, 28 and 48 weeks of age) and its physiological response, i.e. plasma cortisol concentrations (40 weeks of age) were higher in females than males (controls). The result therefore agree with previous reports that adult male sheep show significantly lower responses to fear in a range of both social and non-social situations (Vandenheede and Bouissou, 1993) and that they express lower PMR (Erhard et al., 2004) when compared with adult females. The study by Hernandez et al. $(2009 a, b)$ also reported a higher vocalisation rate in female lambs when assessed $24 \mathrm{~h}$ after birth and proposed that this reflected inherently greater fearfulness of social isolation in females compared to males. The results of the current study also indicated that females were significantly more vocal than males at 28 and 48 weeks of age, and as with previously published data (Hernandez et al., 2009a,b) suggest that vocalisation rate decreases with age. The observation of the sex difference in PMR as early as 8 weeks of age is of particular interest, as it confirms that development of a sexually dimorphic fear reaction in response to social isolation, occurs prior to puberty (39). Further, it indicates that the sexually differentiated nature of this trait may be the result of programming very early in life, for example during in utero development.

At 8 weeks of age, in both males and females, motion within the crate was highest at the beginning of the two minutes test period, potentially representing a heightened fear upon initial isolation. Thereafter, activity rapidly decreased as animals adjusted to their environment. In the females, there was a statistically significant burst of activity at the start of the second minute of the test; however, this was not seen in all animals, and was not seen in later tests. Therefore we concluded that this burst of activity did not reflect a consistent PMR and may have been caused by random large movements in a small subset of animals. Although some animals showed periods of increased activity during the isolation paradigm at both 28 and 48 weeks of age, no consistent patterns, over the eight $15 \mathrm{~s}$ time bins, were seen in either the males or females. The loss of the initial heightened PMR in the later two tests likely reflects persistence of memory of the test or a decrease in fearfulness following maternal separation/social isolation with increased age, as has been suggested previously (Hernandez et al., 2010).

GnRHa treatment begun in the male lambs after PMR was assessed at 8 weeks of age. Thus, the effects of GnRHa treatment on PMR in males were assessed after 20 and 40 weeks of treatment. Since neuroendocrine puberty in sheep occurs later in females (Foster et al., 2002), PMR was assessed twice in females before treatment started and only once after treated animals had received GnRHa for 20 weeks. It is, therefore, not possible with this experimental paradigm to make direct comparisons between the effects of treatment on the two sexes, the duration of treatment and due to context dependent changes in the conduct of the test it is not possible to directly compare results across time. It should also be noted that the experimental paradigm used does not allow the specific isolation of effects mediated directly via $\mathrm{GnRH}$ receptors from those that are induced following suppression of the reproductive axis in treated animals, as $\mathrm{GnRHa}$ treatment prevents activation of the whole of the hypothalamo-pituitary-gonadal axis. In this regard, it should be noted that despite the reduction in circulating steroid concentrations in the $\mathrm{GnRHa}$ treated lambs there were no significant effects on either growth rate or final body weight (data not shown) in either the male or female lambs.

Nevertheless, in the males, 20 weeks of GnRHa treatment was associated with significantly increased PMR. By 48 weeks of age, however, PMR was significantly less in GnRHa treated than untreated males. This result indicates that PMR in the male may change over the course of the pubertal transition and that this change may be affected by the pubertal changes in secretion patterns of $\mathrm{GnRH}$, the gonadotophins and the gonadal steroids. With regard to these changes in PMR, it has previously been reported that anxiety is heightened during adolescence in humans (reviewed in Buchanan et al., 1992) and responsiveness to a stressful situation (Walker et al., 1995; Hascoet et al., 1999) and the bodies neurological response to stress (Shen et al., 2007) peak during adolescence in other animals. While direct temporal comparisons were not possible in this study, for the reasons outlined earlier, the observed suppression of PMR in GnRHa treated male animals at 28 weeks of age, relative to controls, could indicate that the normal expected increase in PMR was 
prevented. Further, the lower PMR observed in the treated males at 48 weeks of age, is in agreement with our previous results in which treated males also expressed behaviour commensurate with lower fearfulness, albeit in a psychologically different setting, namely a risk-taking task (Wojniusz et al., 2011).

When combined, these results suggest a less critical, fearless attitude in long term GnRHa treated males compared to untreated controls. When considering the wider implications of the results of this study, given the neuroplastic changes that occur during this period and the age-dependent neurocognitive and psychophysiological sex-specific and nonsex-specific changes that have reported in many species (Clark and Goldman-Rakic, 1989; Overman, 2004; Overman et al., 2004), it is important to remember that the effects of GnRHa treatment could not only be affected by the time point during maturation at which treatment began, but also how long an individual receives treatment.

Puberty and adolescence in females are usually associated with the development of increased affective physiological symptoms like fearfulness and anxiety. While our results indicated significant sex differences in PMR, there was no effect of GnRHa treatment on PMR. This result contrasts to the results of our earlier study which demonstrated that $\mathrm{GnRHa}$ treatment was associated with effects on higher cognitive functions including decreased initiative taking and inflexible heart rate variability (Wojniusz et al., 2011). The lack of an effect of GnRHa treatment on PMR in females in this study could reflect the shorter duration of GnRHa treatment (N.B. 20 weeks of treatment did result in a significant differences in emotional reactivity between GnRHa treated and control males), however, it could also indicate that PMR in females has greater independence from GnRH/gonadal steroids or that female PMR was already expressed at its maximum compared to males. While such a result is surprising, since a connection between gonadal hormones and anxiety is well established (Meng et al., 2011; Ryan et al., 2011) the published literature in this area has never investigated whether the increases in gonadal steroids, observed at puberty, could be a confounding factor with regard to central effects of $\mathrm{GnRH}$. This question cannot be answered using the results of the current study and indicates an avenue that requires further investigation.

Peripheral cortisol concentrations, the outward response to activation of the HPA axis, are often used as a measure of the physiological response to stress, as following exposure to a stressor, plasma cortisol concentrations increase. Functionally, elevated plasma cortisol concentrations assist other acute physiological responses to stressors such as the fear fight and flight responses classically associated with activation of the sympathetic nervous system. Plasma cortisol concentrations, however, are also central to the longer term modifications an animal makes to chronic stressors, as it helps the body to adapt and function in the face of a homeostatic disturbance. The HPA axis has long been known to be sensitive to the effects of gonadal steroids (Gaskin and Kitay, 1971) and, importantly it is known to be programmed by early developmental stressors (Seckl and Meaney, 2004). Retrospective analysis of the animals in this study indicated that PMR was positively correlated to plasma cortisol concentrations, a result which is not necessarily surprising, given that sheep which are social animals, were studied in social isolation. Interestingly, the observed overall relationship was driven by the GnRHa treated animals and would suggest that the peripubertal actions of $\mathrm{GnRH} /$ gonadal steroids may suppress the physiological response to stressful situations, in this case social isolation.

This study provides important new information about potential extra reproductive effects of $\mathrm{GnRH}$ and the role that GnRH might play in the sex-specific organisation of central brain function, an area which is increasingly recognised as being of critical importance (Cahill, 2006). In addition, this study also establishes GnRHa treatment as an experimental tool to study sex-specific organisation of the brain. The model employed blocked the effects of $\mathrm{GnRH}$ using longterm agonist treatment, starting before puberty, so as to prevent the changes in endogenous pubertal hormonal and any consequent psychological cognitive changes. By selecting peripubertal GnRHa treatment as a model, this study focussed on an important critical period of sex-dependent neuroplasticity, that may be regulated directly and/or indirectly by $\mathrm{GnRH}$ and which may have potential relevance to sex-specific neuropsychiatric pathologies that occur early in life (Cahill, 2006; Hebda-Bauer et al., 2007). The results, however, may also be of importance with regard to normal ageing and other life stages that are associated with significant changes in reproductive endocrinology such as perimenopause. In this regard the timing and nature of the endocrine changes that occur at these times are often sexually dimorphic as are the incidence patterns of many of the later onset neuropsychiatric pathologies such as Alzheimer's disease (Schmidt et al., 2008; Musicco, 2009). It must be remembered, however that the pre-pubertal silencing of sex-specific cognitive differences after birth, their re-emergence or development with puberty and the sex-specific changes in cognitive performance that occur during normal ageing, result from the highly complex interplay that occurs between genetic factors, endocrine molecular mechanisms and brain plasticity that give rise to changes in cognitive performance, behaviour and social interactions, brain function and morphology (Overman, 2004; Sisk and Foster, 2004).

To summarise as PMR provides a measure of cognitive function, we can conclude that pubertal changes in $\mathrm{GnRH}$ secretion are directly or indirectly involved in cognitive changes that occur during the peripubertal period in sheep. As such, prevention of physiological puberty results in individuals with lower PMR than animals that progressed through puberty normally. This may have implications for human treatment paradigms in which puberty is either delayed or blocked using such agonists but also provides interesting avenues to examine effects of age related changes in $\mathrm{GnRH}$ secretion on cognitive function in different species.

\section{Role of the funding source}

The work was funded by the Norwegian Research Council (Norwegian Heath Authorities South - West, HSØ Investigator grant) and the Norwegian School of Veterinary Science.

\section{Conflict of interest statement}

None declared. 


\section{Acknowledgements}

Thanks to staff at the Cochno Farm Research Facility for care and maintenance of animals and Kristine Von Krogh, Sara Rose, Elysia Branson, Sharron Brown, Kelly Breazeale, Flynne Hendry, Chip Lang and Nanette Verboven for help with animal experiments.

\section{References}

Albertson, A.J., Navratil, A., Mignot, M., Dufourny, L., Cherrington, B., Skinner, D.C., 2008. Immunoreactive GnRH type I receptors in the mouse and sheep brain. J. Chem. Neuroanat. 35 (4), 326-333.

Andreano, J.M., Waisman, J., Donley, L., Cahill, L., 2011. Effects of breast cancer treatment on the hormonal and cognitive consequences of acute stress. Psychooncology, http://dx.doi.org/ 10.1002 /pon. 2006

Archer, J., 1973. Tests for emotionality in rats and mice - review. Anim. Behav. 21 (May), 205-235.

Arnold, S., Hubler, M., Reichler, I., 2009. Urinary incontinence in spayed bitches: new insights into the pathophysiology and options for medical treatment. Reprod. Domest. Anim. 44, 190-192.

Boissy, A., 1998. Fear and Fearfulness in determining behaviour. Genetics and the behaviour of domestic animals G.T. Academic Press, San Deago, pp. 67-111.

Boissy, A., Arnould, C., Chaillou, E., Desire, L., Duvaux-Ponter, C. Greiveldinger, L., Leterrier, C., Richard, S., Roussel, S., SaintDizier, H., Meunier-Salaun, M.C., Valance, D., Veissier, I., 2007. Emotions and cognition: a new approach to animal welfare. Anim. Welfare 16, 37-43.

Bowen, R.L., Smith, M.A., Harris, P.L., Kubat, Z., Martins, R.N., Castellani, R.J., Perry, G., Atwood, C.S., 2002. Elevated luteinizing hormone expression colocalizes with neurons vulnerable to Alzheimer's disease pathology. J. Neurosci. Res. 70 (3), 514-518.

Bryan, K., Mudd, J., Richardson, S., Chang, J., Lee, H., Zhu, X., Smith, M., Casadesus, G., 2009. Downregulation of serum gonadotropins is as effective as estrogen replacement at improving menopause-associated cognitive deficits. J. Neurochem. 112, 870-881.

Buchanan, C.M., Eccles, J.S., Becker, J.B., 1992. Are adolescents the victims of raging hormones - evidence for activational effects of hormones on moods and behavior at adolescence. Psychol. Bull. 111 (1), 62-107.

Cahill, L., 2006. Why sex matters for neuroscience. Nat. Rev. Neurosci. 7 (6), 477-484.

Carel, J.C., Eugster, E.A., Rogol, A., Ghizzoni, L., Palmert, M.R., Antoniazzi, F., Berenbaum, S., Bourguignon, J.P., Chrousos, G.P., Coste, J., Deal, S., de Vries, L., Foster, C., Heger, S., Holland, J., Jahnukainen, K., Juul, A., Kaplowitz, P., Lahlou, N., Lee, M.M., Lee, P., Merke, D.P., Neely, E.K., Oostdijk, W., Phillip, M., Rosenfield, R.L., Shulman, D., Styne, D., Tauber, M., Wit, J.M., 2009. Consensus statement on the use of gonadotropin-releasing hormone analogs in children. Pediatrics 123 (4), e752-e762.

Casadesus, G., Webber, K.M., Atwood, C.S., Pappolla, M.A., Perry, G., Bowen, R.L., Smith, M.A., 2006. Luteinizing hormone modulates cognition and amyloid-beta deposition in Alzheimer APP transgenic mice. Biochim. Biophys. Acta 1762 (4), 447-452.

Casey, B.J., Jones, R.M., 2010. Neurobiology of the adolescent brain and behavior: implications for substance use disorders. J. Am. Acad. Child Adolesc. Psychiatry 49 (12), 1189-1201 quiz 1285.

Chu, C., Xu, B., Huang, W., 2010. GnRH analogue attenuated apoptosis of rat hippocampal neuron after ischemia-reperfusion injury. J. Mol. Histol. 41 (6), 387-393.

Clark, A.S., Goldman-Rakic, P.S., 1989. Gonadal-hormones influence the emergence of cortical function in nonhuman-primates. Behav. Neurosci. 103 (6), 1287-1295.
Coit, V.A., Dowell, F.J., Evans, N.P., 2009. Neutering affects mRNA expression levels for the $\mathrm{LH}$ - and $\mathrm{GnRH}$-receptors in the canine urinary bladder. Theriogenology 71 (2), 239-247.

Desire, L., Boissy, A., Veissier, I., 2002. Emotions in farm animals: a new approach to animal welfare in applied ethology. Behav. Process. 60 (2), 165-180.

Erhard, H.W., Boissy, A., Rae, M.T., Rhind, S.M., 2004. Effects of prenatal undernutrition on emotional reactivity and cognitive flexibility in adult sheep. Behav. Brain Res. 151 (1-2), 25-35.

Erhard, H.W., Rhind, S.M., 2004. Prenatal and postnatal exposure to environmental pollutants in sewage sludge alters emotional reactivity and exploratory behaviour in sheep. Sci. Total Environ. $332(1-3), 101-108$.

Fordyce, G., Wythes, J.R., Shorthose, W.R., Underwood, D.W., Shepherd, R.K., 1988. Cattle temperaments in extensive beef herds in Northern Queensland. 2. Effect of temperament on carcass and meat quality. Aust. J. Exp. Agric. 28 (6), 689-693.

Foster, D.L., Padmanabhan, V., Wood, R.I., Robinson, J.E., 2002. Sexual differentiation of the neuroendocrine control of gonadotrophin secretion: concepts derived from sheep models. Reproduction 83-99.

Gaskin, J.H., Kitay, J.I., 1971. Hypothalamic and pituitary regulation of adrenocortical function in hamster - effects of gonadectomy and gonadal hormone replacement. Endocrinology 89 (4), 1047.

Grigorova, M., Sherwin, B.B., Tulandi, T., 2006. Effects of treatment with leuprolide acetate depot on working memory and executive functions in young premenopausal women. Psychoneuroendocrinology 31 (8), 935-947.

Harris, D., Bonfil, D., Chuderland, D., Kraus, S., Seger, R., Naor, Z., 2002. Activation of MAPK cascades by GnRH: ERK and Jun Nterminal kinase are involved in basal and GnRH-stimulated activity of the glycoprotein hormone LHbeta-subunit promoter. Endocrinology 143 (3), 1018-1025.

Hascoet, M., Colombel, M.C., Bourin, M., 1999. Influence of age on behavioural response in the light dark paradigm. Physiol. Behav. 66 (4), 567-570.

Hebda-Bauer, E.K., Luo, J., Watson, S.J., Akil, H., 2007. Female CREB alpha delta-deficient mice show earlier age-related cognitive deficits than males. Neuroscience 150 (2), 260-272.

Hernandez, C.E., Harding, J.E., Oliver, M.H., Bloomfield, F.H., Held, S.D.E., Matthews, L.R., 2009a. Effects of litter size, sex and periconceptional ewe nutrition on side preference and cognitive flexibility in the offspring. Behav. Brain Res. 204 (1), 82-87.

Hernandez, C.E., Matthews, L.R., Oliver, M.H., Bloomfield, F.H., Harding, J.E., 2009b. Effects of sex, litter size and periconceptional ewe nutrition on the ewe-lamb bond. Appl. Anim. Behav. Sci. 120 (1-2), 76-83.

Hernandez, C.E., Matthews, L.R., Oliver, M.H., Bloomfield, F.H., Harding, J.E., 2010. Effects of sex, litter size and periconceptional ewe nutrition on offspring behavioural and physiological response to isolation. Physiol. Behav. 101 (5), 588-594.

Lippmann, M., Bress, A., Nemeroff, C.B., Plotsky, P.M., Monteggia, L.M., 2007. Long-term behavioural and molecular alterations associated with maternal separation in rats. Eur. J. Neurosci. 25 (10), 3091-3098.

Mattson, M.P., Maudsley, S., Martin, B., 2004. A neural signaling triumvirate that influences ageing and age-related disease: insulin/IGF-1, BDNF and serotonin. Ageing Res. Rev. 3 (4), 445-464.

Meaney, M.J., 2001. Maternal care, gene expression, and the transmission of individual differences in stress reactivity across generations. Annu. Rev. Neurosci. 24, 1161-1192.

Meerlo, P., Horvath, K.M., Nagy, G.M., Bohus, B., Koolhaas, J.M., 1999. The influence of postnatal handling on adult neuroendocrine and behavioural stress reactivity. J. Neuroendocrinol. 11 (12), 925-933.

Meethal, S., Smith, M., Bowen, R., Atwood, C., 2005. The gonadotropin connection in Alzheimer's disease. Endocrine 26 (3), $317-325$ 
Meng, F.-T., Ni, R.-J., Zhang, Z., Zhao, J., Liu, Y.-J., Zhou, J.-N., 2011. Inhibition of oestrogen biosynthesis induces mild anxiety in C57BL/6J ovariectomized female mice. Neurosci. Bull. 27 (4), 241-250.

Musicco, M., 2009. Gender differences in the occurrence of Alzheimer's disease. Funct. Neurol. 24 (2), 89-92.

Naninck, E.F.G., Lucassen, P.J., Bakker, J., 2011. Sex differences in adolescent depression: do sex hormones determine vulnerability? J. Neuroendocrinol. 23 (5), 383-392.

Nasjonalt folkehelseinstitutt, 2009. Psykiske lidelser i Norge: Et folkehelseperspektiv Oslo. Nasjonalt folkehelseinstitutt.

Neal, C.R., Weidemann, G., Kabbaj, M., Vazquez, D.M., 2004. Effect of neonatal dexamethasone exposure on growth and neurological development in the adult rat. Am. J. Physiol.-Regul. Integr. Comp. Physiol. 287 (2), R375-R385.

Nelson, C.J., Lee, J.S., Gamboa, M.C., Roth, A.J., 2008. Cognitive effects of hormone therapy in men with prostate cancer: a review. Cancer 113 (5), 1097-1106.

Neufang, S., Specht, K., Hausmann, M., Gunturkun, O., HerpertzDahlmann, B., Fink, G.R., Konrad, K., 2009. Sex differences and the impact of steroid hormones on the developing human brain. Cereb. Cortex 19 (2), 464-473.

Overman, W.H., 2004. Sex differences in early childhood, adolescence, and adulthood on cognitive tasks that rely on orbital prefrontal cortex. Brain Cogn. 55 (1), 134-147.

Overman, W.H., Frassrand, K., Ansel, S., Trawalter, S., Bies, B., Redmond, A., 2004. Performance on the IOWA card task by adolescents and adults. Neuropsychologia 42 (13), 1838-1851.

Palomba, S., Orio Jr., F., Falbo, A., Oppedisano, R., Tolino, A., Zullo, F., 2008. Tibolone reverses the cognitive effects caused by leuprolide acetate administration, improving mood and quality of life in patients with symptomatic uterine leiomyomas. Fertil. Steril. 90 (1), 165-173.

Palomba, S., Orio Jr., F., Russo, T., Falbo, A., Amati, A., Zullo, F., 2004. Gonadotropin-releasing hormone agonist with or without raloxifene: effects on cognition, mood, and quality of life. Fertil. Steril. 82 (2), 480-482.

Parfitt, D.B., Walton, J.R., Corriveau, E.A., Helmreich, D.L., 2007. Early life stress effects on adult stress-induced corticosterone secretion and anxiety-like behavior in the C57BL/ 6 mouse are not as robust as initially thought. Horm. Behav. 52 (4), 417-426.

Pitychoutis, P.M., Zisaki, A., Dalla, C., Papadopoulou-Daifoti, Z., 2010. Pharmacogenetic insights into depression and antidepressant response: does sex matter? Curr. Pharm. Des. 16 (20), 22142223.

Reichler, I.M., Barth, A., Piche, C.A., Jochle, W., Roos, M., Hubler, M., Arnold, S., 2006. Urodynamic parameters and plasma LH/FSH in spayed Beagle bitches before and 8 weeks after GnRH depot analogue treatment. Theriogenology 66 (9), 2127-2136.

Rosati, F., Sturli, N., Cungi, M.C., Morello, M., Villanelli, F., Bartolucci, G., Finocchi, C., Peri, A., Serio, M., Danza, G., 2011. Gonadotropin-releasing hormone modulates cholesterol synthesis and steroidogenesis in SH-SY5Y cells. J. Steroid Biochem. Mol. Biol. 124 (3-5), 77-83.

Ryan, J., Scali, J., Carrière, I., Scarabin, P.-Y., Ritchie, K., Ancelin, M.-L., 2011. Estrogen receptor gene variants are associated with anxiety disorders in older women. Psychoneuroendocrinology 36 , 1582-1586.

Savage, R., Eysenck, H.J., 1964. The definition and measurement of emotionality. Experiments in motivation H. Eysenck. Pergamon Press, Oxford, pp. 292-314.

Schang, A.L., Ngo-Muller, V., Bleux, C., Granger, A., Chenut, M.C., Loudes, C., Magre, S., Counis, R., Cohen-Tannoudji, J., Laverriere, J.N., 2011. GnRH receptor gene expression in the developing rat hippocampus: transcriptional regulation and potential roles in neuronal plasticity. Endocrinology 152 (2), 568-580.

Schmidt, R., Kienbacher, E., Benke, T., Dal-Bianco, P., Delazer, M., Ladurner, G., Jellinger, K., Marksteiner, J., Ransmayr, G., Schmidt, H., Stogmann, E., Friedrich, J., Wehringer, C., 2008. Sex differences in Alzheimer's disease. Neuropsychiatrie 22 (1), $1-15$.

Seckl, J.R., Meaney, M.J., 2004. Glucocorticoid programming. Biobehav. Stress Resp.: Protect. Damag. Effects 1032, 63-84.

Shen, H., Gong, Q.H., Aoki, C., Yuan, M., Ruderman, Y., Dattilo, M., Williams, K., Smith, S.S., 2007. Reversal of neurosteroid effects at alpha4beta2delta GABAA receptors triggers anxiety at puberty. Nat. Neurosci. 10 (4), 469-477.

Sherwin, B.B., Tulandi, T., 1996. "Add-back" estrogen reverses cognitive deficits induced by a gonadotropin-releasing hormone agonist in women with leiomyomata uteri. J. Clin. Endocrinol. Metab. 81 (7), 2545-2549.

Sisk, C.L., Foster, D.L., 2004. The neural basis of puberty and adolescence. Nat. Neurosci. 7 (10), 1040-1047.

Skinner, D.C., Albertson, A.J., Navratil, A., Smith, A., Mignot, M., Talbott, H., Scanlan-Blake, N., 2009. Effects of gonadotrophinreleasing hormone outside the hypothalamic-pituitary-reproductive axis. J. Neuroendocrinol. 21 (4), 282-292.

Spear, L.P., 2009. Heightened stress responsivity and emotional reactivity during pubertal maturation: implications for psychopathology. Dev. Psychopathol. 21 (1), 87-97.

Stewart, A.J., Katz, A.A., Millar, R.P., Morgan, K., 2009. Retention and silencing of prepro-GnRH-II and type II GnRH receptor genes in mammals. Neuroendocrinology 90 (4), 416-432.

Suarez, S.D., Gallup, G.G., 1983. Emotionality and fear in birds - a selected review and reinterpretation. Bird Behav. 5 (1), 22-30.

Turner, A.I., Canny, B.J., Hobbs, R.J., Bond, J.D., Clarke, I.J., Tilbrook, A.J., 2002. Influence of sex and gonadal status of sheep on cortisol secretion in response to ACTH and on cortisol and LH secretion in response to stress: importance of different stressors. J. Endocrinol. 173 (1), 113-122.

Vandenheede, M., Bouissou, M.F., 1993. Sex-differences in fear reactions in sheep. Appl. Anim. Behav. Sci. 37 (1), 39-55.

Walker, C.D., Trottier, G., Rochford, J., Lavallee, D., 1995. Dissociation between behavioral and hormonal responses to the forced swim stress in lactating rats. J. Neuroendocrinol. 7 (8), 615-622.

Wojniusz, S., Vogele, C., Ropstad, E., Evans, N., Robinson, J., Sutterlin, S., Erhard, H.W., Solbakk, A.K., Endestad, T., Olberg, D.E., Haraldsen, I.R.H., 2011. Prepubertal gonadotropin-releasing hormone analog leads to exaggerated behavioral and emotional sex differences in sheep. Horm. Behav. 59 (1), 22-27.

Wood, R.I., Foster, D.L., 1998. Sexual differentiation of reproductive neuroendocrine function in sheep. Rev. Reprod. 3 (2), 130-140. 